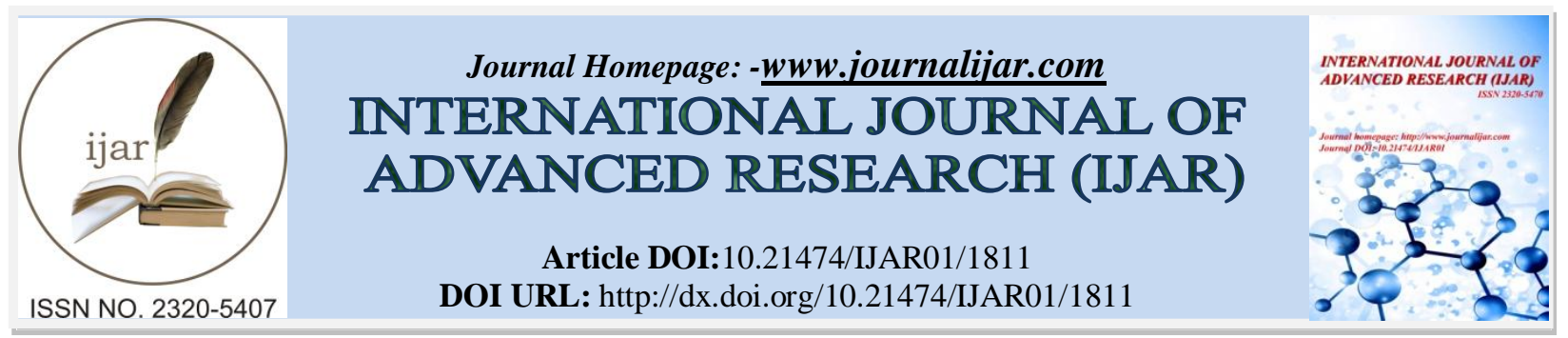

RESEARCH ARTICLE

\title{
MAGNESIUM AND ZINC IN SERUM OF PATIENTS WITH AND WITHOUT DIABETIC RETINOPATHY IN A TERTIARY HEALTH CARE SET-UP IN ASSAM.
}

\author{
Pratim Gupta ${ }^{1}$, R. K. Goswami ${ }^{2}$ and J. J. Kuli ${ }^{3}$.
}

1. Demonstrator, Department of Biochemistry, Assam Medical College and Hospital, Dibrugarh.

2. Ex-Prof \&H.O.D., Department of Biochemistry, Assam Medical College and Hospital, Dibrugarh.

3. Prof \&H.O.D., Department of Ophthalmology, Assam Medical College and Hospital, Dibrugarh.

\section{Manuscript Info}

Manuscript History

Received: 12 August 2016

Final Accepted: 22 September 2016

Published: October 2016

Key words:-

Diabetic Retinopathy, Serum

Magnesium, Serum Zinc.

\section{Abstract}

A cross-sectional study was conducted to determine serum magnesium and serum zinc concentrations in diabetic patients without retinopathy and diabetics with non-proliferative retinopathy. Serum magnesium of $(2.52+0.15) \mathrm{mg} / \mathrm{dl}$ and serum zinc of $(95.18+13.95) \mu \mathrm{g} / \mathrm{dl}$ in patients without retinopathy; and serum magnesium of $(2.32+0.11) \mathrm{mg} / \mathrm{dl}$ and serum zinc of $(68.07+9.41) \mu \mathrm{g} / \mathrm{dl}$ in those with retinopathy was observed. For both parameters, the difference was found to be statistically highly significant $(\mathrm{p}<0.001)$. Although a cause-effect relationship could not be established; lower magnesium levels in patients with non-proliferative retinopathy could be attributed to the observation by earlier workers that lower magnesium triggers endothelial cell dysfunction and thrombogenesis, causes proinflammatory and pro-fibrogenic response, reduces protective enzymes against oxidative stress, and even leads to defective DNA synthesis and repair.Zinc has also been supposed to have antioxidant as well as anti-inflammatory properties and increased oxidative stress contributes to the development of Diabetic Retinopathy; which possibly explained lower zinc concentrations in patients with Diabetic retinopathy. However concrete proof would require follow-up studies of longer duration.

Copy Right, IJAR, 2016,. All rights reserved.

\section{Introduction:-}

A high prevalence of Type 2 diabetes among the adults in Guwahati, Assam, in northeastern part of India had been observed in a sudy (Shah et al, 1998). Research is still on, to add to the knowledge of prevalence of Diabetes and its complications in the northeastern part of India.In India, with the epidemic increase in type 2 diabetes mellitus;as reported by the World Health Organization (WHO), diabetic retinopathy is becoming an important cause of visual disability(Wild et al, 2004). This study is an attempt to find any existing inter-relationship between the important trace elements; magnesium and zinc, and Diabetic Retinopathy.In the larger context, it would enable to comment on necessary measures to influence the concentrations of important trace elements in patients with Diabetes mellitus to mitigate its dreaded microvascular complications. 


\section{Aims and objectives:-}

To determine the concentrations of serum magnesium and serum zinc in diabetic patients, with and without diabetic retinopathy, and find any alterations thereof.

\section{Materials and methods:-}

A total of 42 patients coming to the Retina Clinic (Retina clinic is conducted 2 times a week in Assam Medical College, Dibrugarh) in the Department of Ophthalmology, Assam Medical College, Dibrugarh, Assam; were examined for serum Magnesium and serum Zinc at Advanced Clinical Biochemistry Laboratory under the Department of Biochemistry, Assam Medical College, Dibrugarh.

\section{Inclusion criteria:-}

Patients with history suggestive of Diabetes mellitus, diagnosed clinically (supported by earlier Blood Glucose concentration, $\mathrm{HbA} 1 \mathrm{c} \%$, wherever available); and attending the retina clinic for examination of the retina.Fundoscopic findings, determined by direct and indirect ophthalmoscopy and confirmed by subsequent fundus fluorescein angiography, were taken into account to diagnose cases of diabetic retinopathy.

\section{Exclusion criteria:-}

1. Patients who refused to give consent for the study.

2. Patients with retinopathy other than diabetic retinopathy.

3. Patients with chronic renal failure.

4. Patients on diuretics.

5. Patients on hormonal preparations (other than insulin), antacids, anticonvulsants, lithium, cytotoxic drugs.

6. Patients having acute/chronic diarrhea or malabsorption states.

7. Patients with history of alcohol consumption.

8. Patients on mineral and vitamin supplementation.

9. Patients with endocrinal dysfunction.

10. Patients who are pregnant or lactating.

11. Patients who are critically ill or having incapacitating disorder of the locomotor system.

Identical investigations were conducted on diabetic patients without retinopathy.

\section{Estimation of serum Magnesium :Calmagite method (Gindler et al,1971)}

Principle: Magnesium combines with calmagite in an alkaline medium to form a red coloured complex. Interference of protein and calcium is eliminated by the addition of chelating agent and detergent. Intensity of the colour formed is proportional to the amount of magnesium present in the sample.

Magnesium + calmagite $\longrightarrow$ alkaline medium $\longrightarrow$ Red coloured complex

Manufacterer:- CORAL CLINICAL SYSTEMS

Address:Gitanjali, Dr.Antonio Do Rego Bagh, Bambolim Complex, P.O.Goa-403202, India

Estimation of serum zinc: Colorimetric method (Akita et al,1989; Tetsuo et al, 1991)

Principle: Zinc in an alkaline medium reacts with 2-(5-Nitro-2-pyridylazo)-5-[N-n-propyl-N-(3-sulfopropyl) amino] phenol, disodium salt, dehydrate [NITRO -PAPS] to form a purple coloured complex.Intensity of the complex formed is directly proportional to the amount of zinc present in the sample.

alkaline medium

Zinc+ nitro+PAPS $\longrightarrow$ Purple coloured complex

Manufacterer:- CORAL CLINICAL SYSTEMS

Address:- Gitanjali, Dr.Antonio Do Rego Bagh, Bambolim Complex, P.O.Goa-403202, India

\section{Results:-}

Patients with no diabetic retinopathy had higher levels of mean serum magnesium $(2.52+0.15) \mathrm{mg} / \mathrm{dl}$ as compared to those with non-proliferative diabetic retinopathy who had mean serum magnesium level $(2.32+0.11) \mathrm{mg} / \mathrm{dl}$. This was found to be statistically significant $(p<0.001)$ [Refer: Fig 1]. 
Patients with no diabetic retinopathy had higher mean serum zinc $(95.18+13.95) \mu \mathrm{g} / \mathrm{dl}$ as compared to those with non-proliferative diabetic retinopathy who had a mean serum zinc level of $(68.07+9.41) \mu \mathrm{g} / \mathrm{dl}$ and the difference was statistically significant $(\mathrm{p}<0.001)$. [Refer: Fig 2]

The mean fasting plasma glucose levels was $128.43+32.48 \mathrm{mg} / \mathrm{dl}$, in patients without retinopathy and 144.86+68.86 $\mathrm{mg} / \mathrm{dl}$ in those with non-proliferative retinopathy [Fig 3]. The mean post-prandial plasma glucose levels was $210.67+77.09 \mathrm{mg} / \mathrm{dl}$ in patients with no retinopathy and $223.24+118.53 \mathrm{mg} / \mathrm{dl}$ in those with non proliferative retinopathy[Fig 4].

In a study (McNair et al, 1978) diabetic subjects with severe retinopathy is found to have significantly lower serum magnesium than diabetic subjects without evidence of this complication. The authors suggest, hypomagnesemia to be an additional risk factor in the development and progress of diabetic retinopathy.In another study (Hatwal et al, 1989)serum Magnesium levels in diabetics with retinopathy is significantly lower than in controls, and the workers have opined that patients who have a more severe degree of retinopathy have the lowest magnesium concentration.In patients from Diabetic health camps, outpatients and inpatients of a tertiary care setup of R. L. Jalappa Hospital and Research Centre, in the rural area of Kolar(Navin et al 2013) it is found that, the mean serum magnesium concentration is lower in the diabetic retinopathy group as compared to those in the diabetic subjects.Low Magnesium levels may promote endothelial cell dysfunction and thrombogenesis via increased platelet aggregation and vascular calcifications.Low Magnesium levels may also lead to induction of proinflammatory and profibrogenic response and to reduction of protective enzymes against oxidative stress Moreover, because Magnesium is crucial in DNA synthesis and repair, it is possible that Magnesium deficiency may interfere with normal cell growth and regulation of apoptosis.

The findings in a study (Praveeena et al, 2013) in which plasma zinc concenration is significantly lower in the group with retinopathy than those without retinopathy, corroborates to the finding of the present study.In another study (Gayathri et al, 2013) in Karnataka serum zinc in patients with diabetic retinopathy is seen to be significantly lower than in patients without diabetic retinopathy.In a study (Xiao et al, 2013) it is suggested that several complications of diabetes may be related to increased intracellular oxidants and free radicals which can be attributed to decrease in intracellular $\mathrm{Zn}$ and $\mathrm{Zn}$-dependent antioxidant enzymes. Zinc is also suggested to effectively ameliorate diabetes-related complications in various animal models.

\section{Conclusion:-}

Arguably, lower serum magnesium and lower zinc concentrations in patients with diabetic retinopathy may be a cause or an effect, owing to the cross-sectional study design. The causative role is explained to some extent in the light of studies enumerated earlier.Urinary excretion of Magnesium, especially in patients with unsatisfactory metabolic control, which is a hallmark of patients with diabetic retinopathy suggests the lower magnesium concentration could, in fact, be an effect of the disease.

Altered retinal concentration of Thiobarbituric Acid Reactants (TBARS) and reduced Glutathione; have been reported in animal model under lower plasma zinc concentrations; thus highlighting the role of oxidative stress stimulated by lower zinc levels, in possible causation of retinopahy.Lower zinc concentrations may be the result of hyperzincuria or decreased gastrointestinal absorption of $\mathrm{Zn}$ or both in a Diabe.

To conclude, measurement of these two important trace elements in diabetic patients and their replenishment in deficient states, by means of oral supplementation could act as a possible deterrent to the progression of Diabetic Retinopathy.It would be prudent to add; age of patients, sex of patients, plasma glucose levels, duration since the diagnosis of diabetes mellitus could play a significant role in alterations of serum magnesium and serum zinc. As such their utility as independent and sensitive markers cannot be impressed upon. However the study attempts to encourage future exploration of the novel idea of a stellar role these two minerals could play in Diabetes and its complications, specifically retinopathy.

[Acknowledgement: DBT, Nodal Centre (Tezpur University, Assam) and Dr.(Mrs.)M. Baruah Shandilya, Associate Prof, Deptt. of Ophthalmology, AMCH] 
Fig 1:-Bar-diagram showing the difference between mean serum magnesium concentrations in patients with no retinopathy and those with NPDR

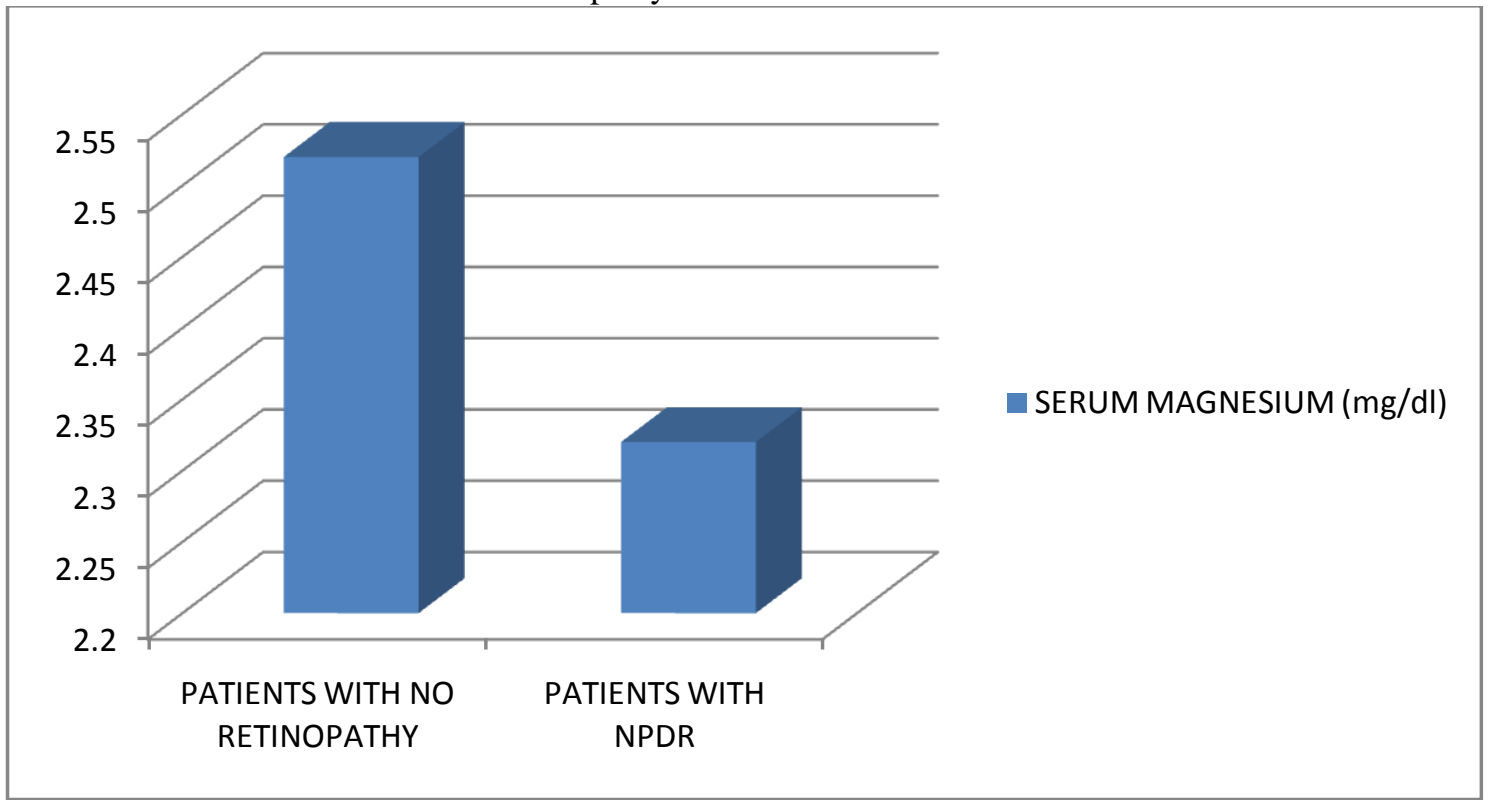

\section{Abbreviation:-}

NPDR-non-proliferative diabetic retinopathy.

Fig 2:-Bar-diagram showing the difference between mean serum zinc concentrations in patients with no retinopathy and those with NPDR.

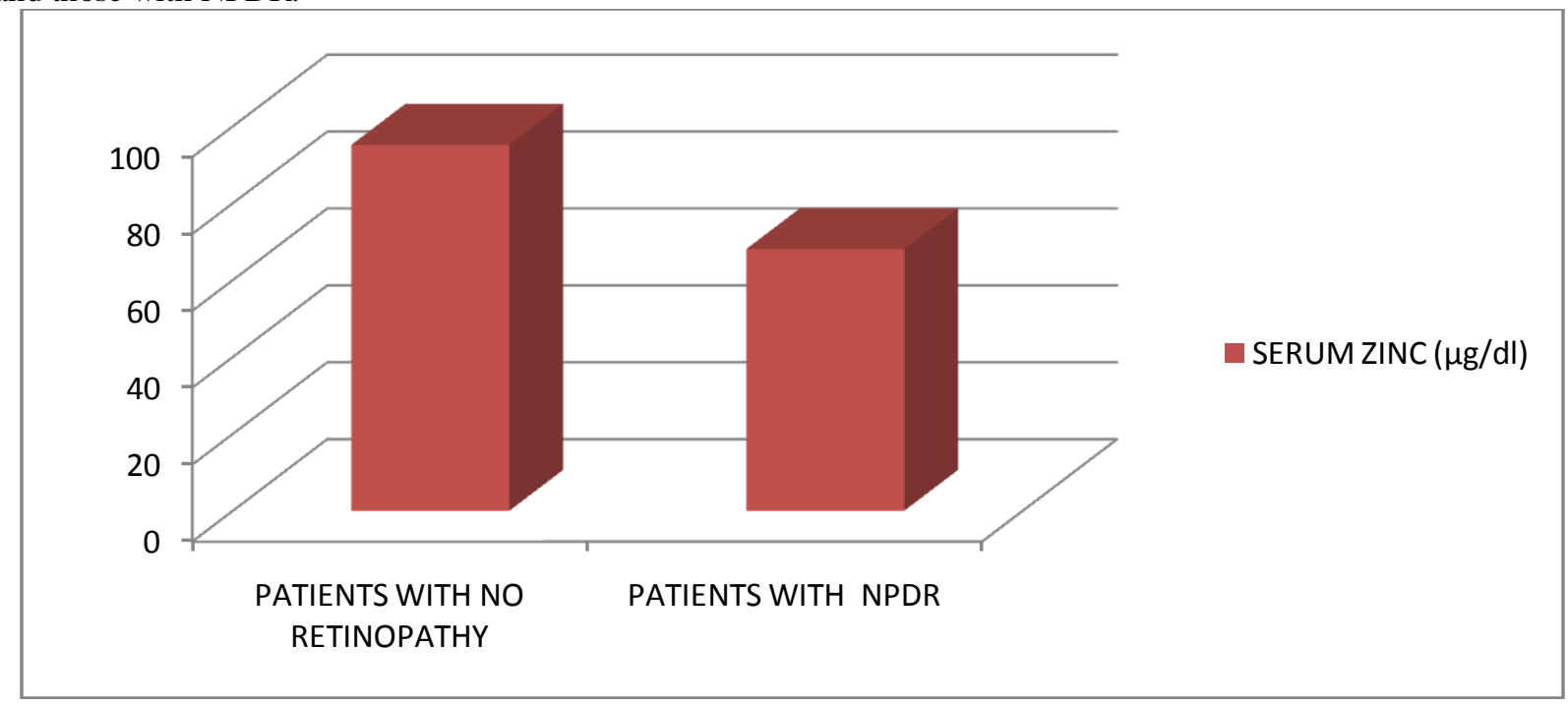

Abbreviation:-

NPDR-non-proliferative diabetic retinopathy. 
Fig 3:-Bar-diagram showing the difference between mean fasting plasma glucose concentrations in patients with no retinopathy and those with NPDR.

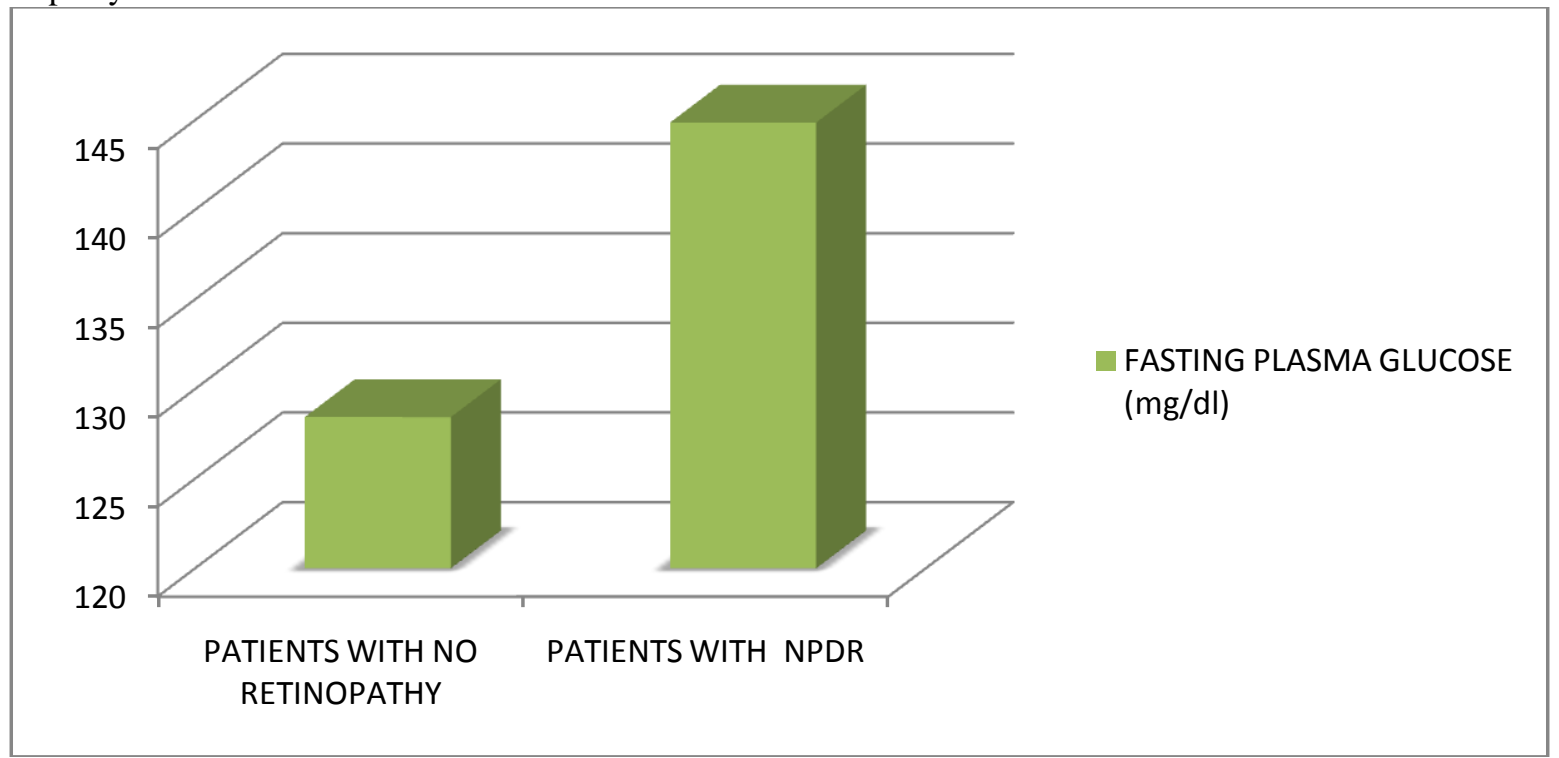

Abbreviation:-

NPDR-non-proliferative diabetic retinopathy.

Fig 4:- bar-diagram showing the difference between mean post-prandial plasma glucose concentrations in patients with no retinopathy and those with NPDR.

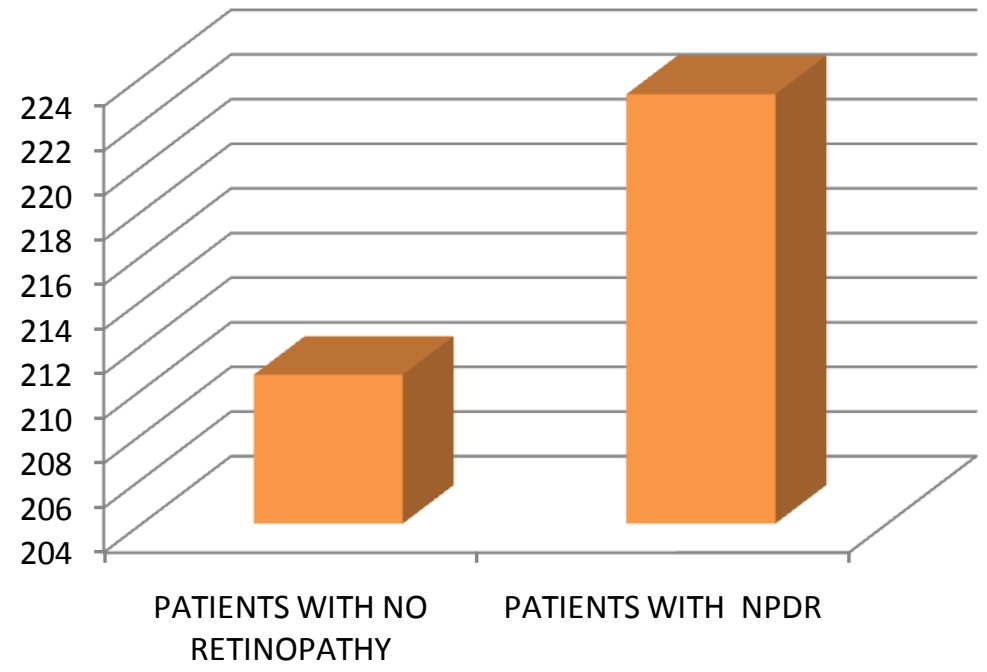

- FASTING POST-PRANDIAL PLASMA GLUCOSE (mg/dl)

\section{Abbreviation:-}

NPDR-non-proliferative diabetic retinopathy.

Table 1:- distribution of patients in terms of age.

\begin{tabular}{|l|l|l|}
\hline AGE (IN YEARS) & PATIENTS WITH NO RETINOPATHY & PATIENTS WITH NPDR \\
\hline$<30$ & 1 & 0 \\
\hline $30-40$ & 2 & 1 \\
\hline $40-50$ & 7 & 6 \\
\hline $50-60$ & 4 & 8 \\
\hline$>60$ & 7 & 6 \\
\hline TOTAL & 21 & 21 \\
\hline
\end{tabular}


Abbreviation:-

NPDR-non-proliferative diabetic retinopathy.

Table 2:-Distribution of patients in terms of gender.

\begin{tabular}{|l|l|l|}
\hline GENDER & $\begin{array}{l}\text { PATIENTS WO WITH NOTIENTS WITH NPDR } \\
\text { RETINOPATHY }\end{array}$ & PATH \\
\hline FEMALES & 8 & 5 \\
\hline MALES & 13 & 16 \\
\hline TOTAL & 21 & 21 \\
\hline
\end{tabular}

Abbreviation:-

NPDR-non-proliferative diabetic retinopathy.

Table 3:-Distribution of patients in terms of duration since the diagnosis of diabetes mellitus.

\begin{tabular}{|l|l|l|}
\hline $\begin{array}{l}\text { DURATION SINCE DIAGNOSIS } \\
\text { OF DIABETES MELLITUS }\end{array}$ & $\begin{array}{l}\text { PATIENTS WITH NO } \\
\text { RETINOPATHY }\end{array}$ & PATIENTS WITH NPDR \\
\hline$<5$ YRS & 14 & 8 \\
\hline $5-10$ YRS & 7 & 11 \\
\hline$>10$ YRS & 0 & 2 \\
\hline TOTAL & 21 & 21 \\
\hline
\end{tabular}

Abbreviation:-

NPDR-non-proliferative diabetic retinopathy.

\section{References:-}

1. Akita Abe, Yiamashita, S., (1989) Clin. Chem.35/4 :552 - 554

2. Gindler, E., et al.(1971), clin.chem.17:662

3. Hatwal A, Gujral AS, Bahtia RPS, et al. (1989): Association between hypomagnesaemia and diabetic retinopathy. Acta Ophthalmol 67:714-716

4. Lal M, Sudha K, Shetty B and Gayathri M Rao.Influence of modified levels of plasma magnesium, $\mathrm{Cu}, \mathrm{Zn}$ and Iron levels on thiols and protein status in diabetes mellitus and diabetic retinopathy.IJAPBS.2013;2(1):67-72.

5. McNair P, Christiansen C, Madsbad S, Lauritzen E, Faber O, Binder C et al. Hypomagnesemia, a risk factor in diabetic retinopathy. Diabetes. 1978;27(11):1075--1077.

6. Miao X, Sun W, Miao L, Fu Y, Wang Y, Su G et al. Zinc and diabetic retinopathy. Journal of Diabetes Research. 2013.Article ID 425854.

7. Navin S, Krishnamurthy N, Ashakiran S, and C D Dayanand, The Association of Hypomagnesaemia, High Normal Uricaemia and Dyslipidaemia in the Patients with Diabetic Retinopathy, J Clin Diagn Res. Sep 2013; 7(9): 1852-185.

8. Praveeena S, Sujatha P and Ganesh B.Study of micronutrients in diabetic retinopathy.Journal of Evolution of Medical and Dental Sciences.2013; 2(6):531-37.

9. Shah S K, Saikia M, Snehalatha C, Ramachandran A High prevalence of type 2 diabetes in urban population in north eastern india. Int. J. Diab. Dev. Countries (1998), VOL. 18:97-100.

10. Tetsuo Makino, (1991) Clin. Chem.Acta, 197: 209-220.

11. Wild S, Roglic G, Green A, Sicree R, King H.Global prevalence of diabetes, estimates for the year 2000 and projections for 2030. Diabetes Care 2004; 27 : 1047-53 